\title{
DNA from historical and trophy samples provides insights into white shark population origins and genetic diversity
}

\author{
Chrysoula Gubili ${ }^{1,9, *}$, Cory E. C. Robinson ${ }^{1, *}$, Geremy Cliff ${ }^{2}$, Sabine P. Wintner ${ }^{2}$, \\ Eleonora de Sabata ${ }^{3}$, Sabina De Innocentiis ${ }^{4}$, Simonepietro Canese ${ }^{4}$, \\ David W. Sims ${ }^{5,6,7}$, Andrew P. Martin ${ }^{8}$, Leslie R. Noble ${ }^{1, * *}$, Catherine S. Jones ${ }^{1, * *, * * *}$ \\ ${ }^{1}$ Institute of Biological and Environmental Science, School of Biological Sciences, University of Aberdeen, Zoology Building, \\ Tillydrone Avenue, Aberdeen AB24 2TZ, UK \\ ${ }^{2}$ KwaZulu-Natal Sharks Board, Private Bag 2, Umhlanga Rocks 4320, and Biomedical Resource Unit, \\ University of KwaZulu-Natal, Durban 4000, South Africa \\ ${ }^{3}$ MedSharks, via Ruggero Fauro 82, 00197 Rome, Italy \\ ${ }^{4}$ Italian National Institute for Environmental Protection and Research, Marine Molecular Biology Lab (BMM), \\ via Vitaliano Brancati 60, 00166 Rome, Italy \\ ${ }^{5}$ Marine Biological Association of the United Kingdom, The Laboratory, Citadel Hill, Plymouth PL1 2PB, UK \\ ${ }^{6}$ Marine Biology and Ecology Research Group, School of Biological Sciences, University of Plymouth, Drake Circus, \\ Plymouth PL4 8AA, UK \\ ${ }^{7}$ Ocean and Earth Science, National Oceanography Centre Southampton, University of Southampton, Waterfront Campus, \\ European Way, Southampton SO14 3ZH, UK \\ ${ }^{8}$ Department of Ecology and Evolutionary Biology, University of Colorado, N122 Ramaley, Boulder, Colorado 80309, USA \\ ${ }^{9}$ Present address: Coordenação de Biodiversidade, Instituto Nacional de Pesquisas da Amazônia, Av. André Araújo 2936, \\ Manaus, AM 69060-001, Brazil
}

\begin{abstract}
Characterizing genetic variation by retrospective genotyping of trophy or historical artifacts from endangered species is an important conservation tool. Loss of genetic diversity in top predators such as the white shark Carcharodon carcharias remains an issue, exacerbated in this species by declining, sometimes isolated philopatric populations. We successfully sequenced mitochondrial DNA (mtDNA) D-loop from osteodentine of contemporary South African white shark teeth (from 3 jaws), and from 34 to 129 yr old dried cartilage and skin samples from 1 Pacific Ocean and 5 Mediterranean sharks. Osteodentine-derived sequences from South African fish matched those derived from an individual's finclips, but were generally of poorer quality than those from skin and cartilage of historical samples. Three haplotypes were identified from historical Mediterranean samples $(\mathrm{n}=5)$; 2 individuals had unique sequences and 3 shared the contemporary Mediterranean haplotype. Placement of previously undescribed mtDNA haplotypes from historical material within both the Mediterranean and Pacific clades fits with the accepted intraspecific phylogeny derived from contemporary material, verifying our approaches. The utility of our methodology is in its provision of additional genetic resources from osteodentine (for species lacking tooth pulp) and cartilage of rare and endangered species held in often uncurated, contemporary and historical dry collections. Such material can usefully supplement estimates of connectivity, population history, and stock viability. We confirm the depauperate haplotype diversity of historical Mediterranean sharks, consistent with founding by a small number of Pacific colonizers. The consequent lack of diversity suggests serious challenges for the maintenance of this top predator and the Mediterranean ecosystem.
\end{abstract}

KEY WORDS: Teeth · White shark · Carcharodon carcharias $\cdot$ Museum specimens $\cdot$ Mitochondrial DNA · Genotyping $\cdot$ Mediterranean $\cdot$ Cartilage $\cdot$ Osteodentine

\footnotetext{
${ }^{*}$ Authors contributed equally

${ }^{* *}$ Joint last authors

${ }^{* * *}$ Corresponding author: c.s.jones@abdn.ac.uk
}

(C) The authors 2015. Open Access under Creative Commons by Attribution Licence. Use, distribution and reproduction are unrestricted. Authors and original publication must be credited. Publisher: Inter-Research · www.int-res.com 


\section{INTRODUCTION}

Life-history characteristics of elasmobranchs (long life span, slow maturation, long gestation periods, and low fecundity) make them highly vulnerable to fishing pressure (Baum et al. 2003). Recent estimates suggest that $25 \%$ of described sharks and rays are threatened with extinction (according to IUCN Red List criteria; Dulvy et al. 2014). This makes the development of responsible sustainable stock exploitation and conservation strategies difficult (Dulvy \& Forrest 2009), especially as only $8 \%$ of threatened shark and ray species are currently protected (McClenachan et al. 2012). Such difficulties may be exacerbated in species known to exhibit some form of natal philopatry. Here widespread protection in conjunction with local conservation efforts is required to preserve the management unit (MU; Avise 1995), as defined by connectivity sufficiently low that each population should be monitored and managed separately. In these instances, and where top predators or keystone species are established from small founding propagules, there is particular urgency to identify the tipping point where anthropogenic pressures begin to impact genetic diversity, and so the resilience of a stock. Supporting this view, Spielman et al. (2004) suggest there is significant erosion of genetic diversity in advance of apparent demographic declines, and a recent meta-analysis demonstrated a significant effect of fishing pressure on genetic diversity (Pinsky \& Palumbi 2014). Hence, development of sustainable management strategies may benefit from incorporating longitudinal assessments of regional fishing pressure and declines in genetic diversity derived from a comparison of historical and contemporary material.

The great white shark Carcharodon carcharias (Linnaeus, 1758) is an apex predator, capable of long-distance migrations (Bonfil et al. 2005), displaying complex segregation by size and sex (Domier \& Nasby-Lucas 2013, Jewell et al. 2013, Kock et al. 2013), and natal philopatry (Pardini et al. 2001, Jorgensen et al. 2010). It is classified as 'Vulnerable' in the IUCN Red List, and in 2004 was placed on CITES Appendix II. Many populations have undergone dramatic declines (Baum et al. 2003), and first estimates of white shark abundance in Californian waters seemed to suggest substantially smaller numbers than other large marine predators (Chapple et al. 2011), prompting urgent calls for protection. However, a recent study refuted this, indicating a greater estimated population size in the eastern Pacific (Burgess et al. 2014), while historic abundance trends in the western North Atlantic suggest recovering populations (Curtis et al. 2014). Nonetheless, genetic analysis of Australian white shark populations suggests estimates of contemporary effective population sizes approach levels at which adaptive potential may be lost (Blower et al. 2012). A similar concern was expressed following the observation that several contemporary white sharks sampled from across the Mediterranean all had the same Pacific clade mitochondrial haplotype (Gubili et al. 2011). In Turkish waters white sharks are considered extinct in the Sea of Marmara, although contemporary records of neonates in the northern Aegean Sea suggest nearby breeding grounds (Kabasakal 2014). These conflicting views and observations illustrate that the impact of anthropogenic effects on connectivity, and consequently genetic diversity and effective population size, are probably complex and currently poorly known for this species throughout most of its range.

Population genetic analysis has been useful for shark management and conservation efforts (Dudgeon et al. 2012). However, the veracity of population and demographic parameters estimated from analysis of DNA sequences depends to a large degree on sampling a reasonable number of individuals. For example, between-population migration estimates from molecular data improve with large sample sizes ( $~ 50$ individuals) (Paetkau et al. 2004). Unfortunately, because white sharks are rare, large, and difficult to sample in an unpredictable marine environment, tissue for DNA analysis is difficult to obtain, hindering application of molecular genetics to address some conservation questions. Yet, in common with other apex predators, the many trophy artifacts, as well as jaws and teeth of white sharks, held in public and private collections may permit retrospective population genetic analysis, provided these dried specimens still contain intact DNA fragments of sufficient size to be reliably and routinely recovered and characterized.

Here we explore the potential of contemporary white shark teeth, containing only osteodentine (Vennemann et al. 2001) and no pulp cavity (filled with living connective tissue and odontoblasts), as a source of DNA. While Ahonen \& Stow (2008) successfully extracted DNA from the pulp cavity of teeth and jaws of several shark species from the Carcharhinidae family, DNA recovery from dentine presents some technical challenges, but has been successful from mammal teeth (Pääbo 1989, Höss \& Pääbo 1993, Pfeiffer et al. 1998). Additionally, we extended our investigations to skin and cartilage recovered from trophy specimens collected from the Mediterranean and Pacific Ocean. 
In this study, we report on the first attempt to extract and amplify mitochondrial DNA (mtDNA) of a series of small overlapping contiguous sequences (Fulton \& Stiller 2012) from the osteodentine of contemporary white shark teeth from South Africa. We have also used this method to recover sequences from dried skin and jaw cartilage of Mediterranean and Pacific Ocean white sharks collected 34 to 129 yr ago. This resource was used to test whether the prevailing Pacific origin hypothesis (Gubili et al. 2011) of Mediterranean white sharks can be refuted by sequencing the D-loop of more individuals.

\section{MATERIALS AND METHODS}

\section{Sample preparation and extraction protocols}

Jaw samples and small pieces of fins were taken from 3 individuals caught in beach protection nets (Cliff et al. 1989) at different locations along the east coast of South Africa (SA; KwaZulu-Natal) between 2004 and 2005 (Table 1). In addition, we assembled a collection of museum jaw cartilage and uncurated, dried tissue samples from 7 white sharks collected 33 to $128 \mathrm{yr}$ ago from the Mediterranean Sea and Atlantic and Pacific Oceans (Table 1).

Teeth $(n=3-4)$ from each of the South African jaws were detached, cleaned, and washed overnight with Virkon (Day-Impex Limited). After drying, teeth were cut by a rotary power tool (FMTC 140HTK, Performance TM). Tool, cutting parts, surfaces, and vice were washed with $70 \%$ ethanol and $10 \%$ sodium hydroxide. Enamel was removed, and the osteoden- tine was placed in a $1.5 \mathrm{ml}$ microcentrifuge tube. Osteodentine from each tooth (averaging $0.12 \mathrm{~g}$ ) was initially washed, and subsequently crushed to powder on a Spex 6750 freezer mill (Spex SamplePrep).

Fragments (0.10 to $0.25 \mathrm{~g}$ ) of historical tissue and jaw cartilage from Mediterranean, Atlantic and Pacific Ocean white sharks were rehydrated for $24 \mathrm{~h}$ in $1 \times$ TE buffer (10 mM Tris pH 7.5, 1 mM EDTA) to reduce aerosol contamination and increase rate of digestion. A standard phenol extraction protocol (Sambrook et al. 1989) was employed to obtain genomic DNA from all samples, modified by an additional $40 \mu \mathrm{l}$ of Proteinase $\mathrm{K}$ added prior to final overnight incubation $\left(55^{\circ} \mathrm{C}\right)$. Finclip DNA extractions for verification of tooth-derived sequences from contemporary SA individuals were performed in a different laboratory.

\section{Contamination controls}

Stringent measures employed in successful ancient/ historical DNA projects (Valentine et al. 2008, McMenamin \& Hadly 2012) were instigated to eliminate contamination risks. All DNA extractions, including those from teeth, took place in laboratories free of contemporary shark material, and separate tools were designated for use on historical tissue and cleaned with $25 \%$ sodium hypochlorite solution between samples. Three tissue extractions were performed for each sample, with the addition of a negative control consisting of only reaction reagents. PCR took place in a separate DNA-free location and included 2 negative controls. Replicate amplifications $(n=3-5)$ were performed for each sample, of which 2

Table 1. Carcharodon carcharias. Details of each sampled South African white shark (supplied by the KwaZulu-Natal Sharks Board), and historical material (obtained from museum and private collections). Tissue type used in analysis is also provided. Haplotype refers to the $749 \mathrm{bp}$ partial mitochondrial DNA D-loop sequence haplotype referred to in Fig. 2. F: female; M: male; TL: total length; -: unknown

\begin{tabular}{|c|c|c|c|c|c|c|c|}
\hline Sample ID & Capture date & Capture location & Sex & $\mathrm{TL}(\mathrm{mm})$ & Mass (kg) & Tissue type & Haplotype \\
\hline \multicolumn{8}{|c|}{ Contemporary samples } \\
\hline DUR04039 & 4 Nov 2004 & Durban, South Africa & $\mathrm{F}$ & 2210 & 100 & Teeth \& finclip & - \\
\hline RB05086 & 24 Oct 2005 & Richards Bay, South Africa & M & 2598 & 170 & Teeth \& finclip & - \\
\hline ISP05004 & 8 Sep 2005 & Ispingo, South Africa & $\mathrm{M}$ & 2570 & 134 & Teeth \& finclip & - \\
\hline \multicolumn{8}{|c|}{ Historical samples } \\
\hline GWMD3 & 1 May 1900 & Atlantic & - & - & - & Jaw cartilage & - \\
\hline GWMD10 & 1885 & Port Jackson, NSW, Australia & M & - & - & Chondocranium & $\mathrm{H} 20$ \\
\hline GWMD11 & 10 Dec 1891 & Liguria, Monterosso, Italy & $\mathrm{F}$ & $\sim 6000$ & - & Jaw cartilage & $\mathrm{H} 24$ \\
\hline GWMD12 & 1900 & Toscana, Lucca, Viareggio, Italy & $\mathrm{F}$ & - & - & Finclip, full specimen & H1 \\
\hline GWMD20 & 29 May 1953 & Tunara, Favignana, Italy & $\mathrm{F}$ & - & - & Dried fin, trophy board & $\mathrm{H} 2$ \\
\hline GWMD21 & 4 Apr 1980 & Tunara, Favignana, Italy & $\mathrm{F}$ & - & - & Dried fin, trophy board & $\mathrm{H} 2$ \\
\hline GWMD15 & - & Palermo, Sicily, Italy & - & - & - & Jaw cartilage & $\mathrm{H} 2$ \\
\hline
\end{tabular}


to 3 products were sequenced in both forward and reverse directions to ensure the veracity of results. Sequence chromatograms were screened independently by eye and verified by colleagues to ensure accuracy of base calling.

\section{MtDNA analyses}

Five pairs of primers were designed using Primer Premier 5.0 (www.PremierBiosoft.com) to amplify independently 5 overlapping fragments, from 135 to $286 \mathrm{bp}$, of the D-loop sequence (Table 2, Fig. 1). However, due to A+T-rich regions of the mtDNA, there are necessarily overlaps with 3 pairs: Dloop1Reverse with D-loop2Forward (9 bases), Dloop3Reverse with D-loop4Forward (11 bases), and D-loop4Reverse with D-loop5Forward (14 bases). Nevertheless, each overlap contained only a single

Table 2. Carcharodon carcharias. Primer sequences and PCR (polymerase chain reaction) conditions for amplification of overlapping fragments of the white shark mtDNA D-loop

\begin{tabular}{|c|c|c|c|c|}
\hline Primer & Primer sequence $\left(5^{\prime}-3^{\prime}\right)$ & $\begin{array}{l}\text { Annealing } \\
\text { temp. }\left({ }^{\circ} \mathrm{C}\right)\end{array}$ & $\begin{array}{l}\text { Amplicon } \\
\text { size (bp) }\end{array}$ & $\begin{array}{c}\mathrm{MgCl}_{2} \\
(\mathrm{mM})\end{array}$ \\
\hline D-loop1 & $\begin{array}{l}\text { ACA CGC ACG TAT ATT GCT AAC TG } \\
\text { CCA AAA CTG AAA GGG ATA GAG AG }\end{array}$ & 54 & 135 & 2.5 \\
\hline D-loop2 & $\begin{array}{l}\text { ATT ATG GCG TCA ATC TCT CTA TC } \\
\text { GAG GCT CAT CTG GGA CAC TAA G }\end{array}$ & 54 & 135 & 2.5 \\
\hline D-loop3 & $\begin{array}{l}\text { TAG AAG AGT GTC GAG GGG AGT AC } \\
\text { AAT CCT CAT CAA CTG AAC AAA CC }\end{array}$ & 54 & 286 & 2.5 \\
\hline D-loop4 & $\begin{array}{l}\text { TAA ATG TCA GGT TTG TTC AGT TG } \\
\text { ATC CCC ATT CAT CTA CTT ACA GC }\end{array}$ & 48 & 228 & 1.5 \\
\hline D-loop5 & $\begin{array}{l}\text { AAT GAA ATT GCT GTA AGT AGA TG } \\
\text { CTG AAT GCT GTC AAA ACA TG }\end{array}$ & 48 & 245 & 2.5 \\
\hline D-loop7 & $\begin{array}{l}\text { CGT ATC CAT TAT GGC GTC AAT CTC T } \\
\text { GCG TCA AGA TTT ATT TTC CAC }\end{array}$ & Т $60-63$ & 206 & 2.5 \\
\hline
\end{tabular}

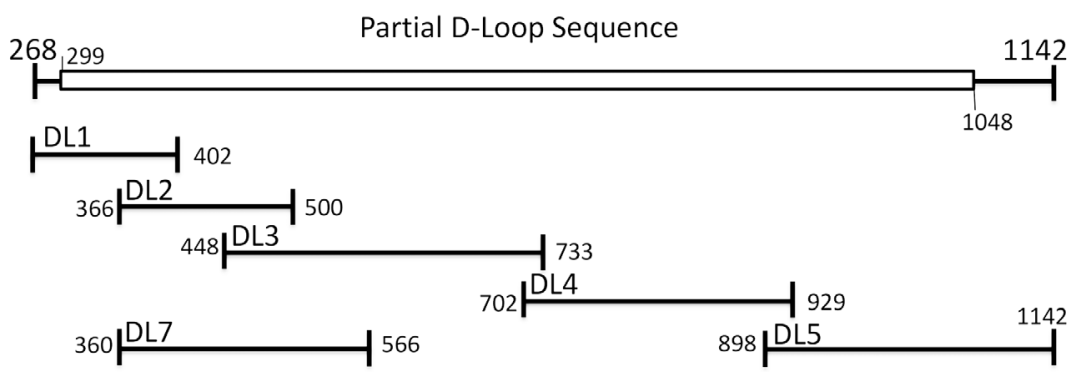

Fig. 1. Carcharodon carcharias. Schematic of partial mitochondrial D-loop sequence. Black bars show primer positions of Amplicons 1 to 5 and 7 of the D-loop (DL). White box along the partial sequence represents 749 base pairs of the sequence used in this analysis. Start and stop positions are provided for each primer amplicon and sequence used, and correspond to regions of the full mitochondrial DNA (mtDNA) polymorphic site, the remaining amplicons allowing adequate haplotypic assignment (Pardini et al. 2001). Two additional primers were designed to target polyhisms diagnostic of potential Atlantic haploas distinct from those of Mediterranean or (D-loop7) was successfully used in this analysis, yielding a $206 \mathrm{bp}$ product.

Ten nanograms of genomic DNA were used for $20 \mu \mathrm{l}$ PCRs (polymerase chain reactions) containing $1 \times \mathrm{NH}_{4}$ buffer, $200 \mu \mathrm{M}$ of each dNTP, $\mathrm{MgCl}_{2}$ (1.5$2.5 \mathrm{mM}$; Table 2), $0.3 \mu \mathrm{M}$ of each primer, and $1.0 \mathrm{U}$ of AmpliTaq Gold ${ }^{\mathrm{TM}}$ DNA polymerase (Applied Biosystems) on a Biometra T-Gradient thermal cycler. Amplification conditions consisted of initial denaturation for $5 \mathrm{~min}$ at $94^{\circ} \mathrm{C}$, followed by 40 cycles of $30 \mathrm{~s}$ at $94^{\circ} \mathrm{C}_{i} 30 \mathrm{~s}$ annealing (temperature dependent on the primers used; Table 2), $30 \mathrm{~s}$ at $72^{\circ} \mathrm{C}_{i}$ and a final extension step of $10 \mathrm{~min}$ at $72^{\circ} \mathrm{C}$. The same quantity of genomic DNA from historical material was used for an initial $20 \mu \mathrm{l}$ PCR using the primers GWSF6 (5' TTG GCT CCC AAA GCC AAG ATT CT 3') and PheCaCaH (5' CTA CTT AGC ATC TTC AGT GCC 3') (Gubili 2009) to achieve partial amplification of the full mitochondrial D-loop. The resulting PCR products, including all negative controls, were diluted 1/10, of which 1 to $3 \mu \mathrm{l}$ was used for subsequent semi-nested PCRs of $40 \mu$ l volume, for all 6 overlapping primer sets. Positive controls were not used, as other DNA protocols for historical studies deem them to be of little value (Fulton \& Stiller 2012). All amplicons were assayed on $2 \%$ agarose gels, purified using the QIAGEN QIAquick PCR purification kit following the manufacturer's instructions, and commercially sequenced.

To confirm the suitability of teeth as a source of DNA, sequences obtained from South African tooth samples were aligned to those generated from fin tissues of the same individuals, using ProSeq 3.2 (Filatov 2002). To determine their similarity to other available haplotypes, sequences derived from historical Mediterranean samples were aligned to white shark sequences available on GenBank, in- 
cluding 4 contemporary Mediterranean sequences (HQ540294 to HQ540296, Gubili et al. 2011; JF715925) and 91 sequences from worldwide locations (AY026196 to AY026224, Pardini et al. 2001; GU00 2302 to GU002321, Jorgensen et al. 2010; HQ414073 to HQ414086, Blower et al. 2012; KC914387, Chang et al. 2014; KC511601 to KC511626). These specifically included sequences from proximal populations (such as South Africa and North West Atlantic) which may be considered as potential source populations for the Mediterranean. Base pair positions with gaps/missing data were excluded from analysis. Haplotypes, haplotypic diversity, and average pairwise sequence differences were obtained using DnaSP 5.10.1 (Librado \& Rozas 2009). A haplotype genealogy was constructed in HAPVIEW following the method of Salzburger et al. (2011) using a phylogenetic tree derived in PhyML v3.0 (Guindon \& Gascuel 2003, Guindon et al. 2010) following 10000 bootstraps using GTR+G+I as the evolutionary model inferred by JMODELTEST (Posada 2008).

\section{RESULTS}

\section{DNA amplification from contemporary teeth}

D-loop PCR products were recovered for each SA individual, although not all amplifications were equally successful. All sets of primers yielded a PCR product of the expected size in at least 1 individual. PCR using primer sets D-loop1, D-loop2, and D-loop4 yielded a product of the expected size in all samples $(100 \%)$. Larger fragments produced by D-loop3 (286 base pairs [bp]) and D-loop5 (245 bp) primers were successful in only 1 (Durban) in 3 samples $(33.33 \%)$, indicating that amplification success is dependent upon size of the target fragment due to the poor quality of template DNA ( $\mathrm{p}<$ $\left.0.05 ; \mathrm{X}_{27}^{2}=40.4\right)$. When aligned, the 5 overlapping sequences amounted to $874 \mathrm{bp}$ (from Position 268 to 1142) of the D-loop. Sequences obtained from tooth samples were identical to those generated from the fin tissues.

\section{MtDNA amplification from historical material}

DNA was extracted from 7 historical samples (Table 1). The semi-nested PCR protocol was $74 \%$ successful across all amplicons, improving on the much lower success rate $(26 \%)$ and poor reproducibility of non-nested reactions across all D-loop primer sets. D-loop2 was initially used on historical material, but discarded due to the poor quality of the sequence produced. No correlations between the age of sample and semi-nested PCR success rate were detected for each primer pair $(\mathrm{R}=-0.356$ to 0.373$)$. All forward and reverse sequences were identical and confirmed as Carcharodon carcharias by BLAST searches. Low-quality amplification for the D-loop4 amplicon from the historical Atlantic sample (GW MD3) meant it was excluded from the final analysis. However, when a smaller segment (510 bp) of sequence was analysed, this sample displayed a unique haplotype found within the Atlantic/South African grouping (data not shown). Assembled contigs from each of 6 remaining historical samples produced in each case a $749 \mathrm{bp}$ partial sequence of the mtDNA control region (Fig. 1).

The historic samples were aligned to the 96 known contemporary white shark mtDNA sequences available in GenBank, revealing 88 polymorphic sites distinguishing 55 different haplotypes. These haplotypes were assembled into a network with 2 main lineages separated by a minimum of 30 nucleotide substitutions: one lineage was composed mainly of North West Atlantic and South African sequences, while the other included all Pacific haplotypes (Fig. 2). Contemporary Mediterranean samples ( $\mathrm{n}=4$; GenBank HQ540294 to HQ540296, Gubili et al. 2011; JF715925) exhibited a single haplotype (H2), shared with 3 historical Mediterranean samples (GWMD15, 20, and 21; Fig. 2). Two additional historical Mediterranean haplotypes (H1, GWMD12, Toscana, Italy; H24, GWMD11, Monterosso, Italy) were identified from single individuals. Mediterranean haplotypes showed little differentiation from those of Pacific sharks; for example, only 3 mutational steps separate the common Mediterranean haplotype (H2) from the Northeast Pacific/Australia/New Zealand (H19) haplotype, and 6 steps separate it from the Southwest Pacific (Taiwan) haplotype (H6) (Fig. 2). The newly described historical Mediterranean haplotype H24 was separated from the common Mediterranean haplotype (H2) by only 3 mutational steps, and from Northeast Pacific/Australia/New Zealand (H19) and Southwest Pacific (Taiwan) haplotypes (H6) by 4 steps and 7 steps, respectively (Fig. 2). However, the historical Mediterranean haplotype H1, while separated by 6 mutational steps from the common Mediterranean haplotype H2, was only 2 steps removed from contemporary Australian/New Zealand sequences (H9); placing it firmly with contemporary Pacific haplotypes. Estimates of ave- 


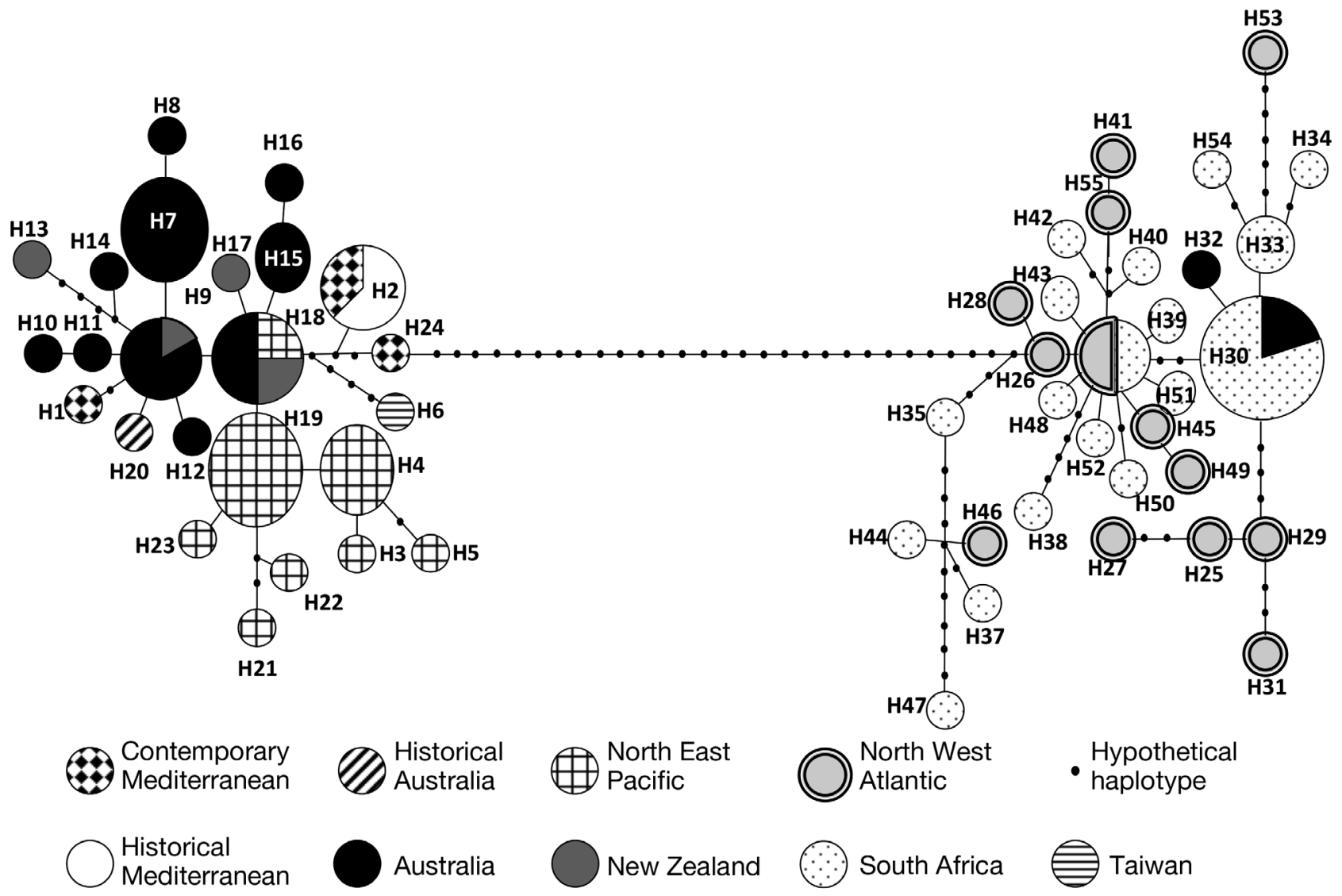

Fig. 2. Carcharodon carcharias. Median-joining network from a 749 bp partial mtDNA D-loop sequence consisting of 55 haplotypes derived from 6 historical and 96 contemporary white shark sequences, showing the low genetic differentiation of contemporary (H2) and historical (H1, H2, and H24) Mediterranean samples from Pacific (North East Pacific, Australia, and New Zealand) sharks. Circle size is proportional to the frequency of each haplotype; shading represents capture locality; small black circles represent hypothetical haplotypes; single mutational steps are assumed between haplotypes

rage pairwise sequence differences and haplotypic diversity were higher in the historical compared to the contemporary Mediterranean samples (Table 3). Haplotype H20, recovered from a historical Australian chondrocranium (GWMD10; New South Wales), was closely related to a contemporary Australian/New Zealand haplotype (H9), differing by a single mutational step.

Table 3. Carcharodon carcharias. Estimates of diversity for the contemporary and historical Mediterranean samples

\begin{tabular}{|lcc|}
\hline & Contemporary & Historical \\
\hline Sample size, $\mathrm{n}$ & 5 & 5 \\
Haplotype number & 1 & 3 \\
Average pairwise difference & 0 & 3.00 \\
Haplotype diversity $\left(1-\Sigma p^{2}\right)$ & 0 & 0.70 \\
Nucleotide diversity & 0 & 0.00411 \\
\hline
\end{tabular}

\section{DISCUSSION}

This is the first successful attempt to extract genomic DNA from contemporary white shark teeth, which do not contain pulp, and from dry tissue and jaw cartilage samples collected 34 to 129 yr ago. We report attempts to reconstruct larger mtDNA sequences by combining small overlapping amplicons to confirm the veracity of this methodology on shark teeth, and demonstrate its capacity for genotyping white sharks, determining their potential provenance through phylogeographic analyses of restricted samples from as little as 0.1 to $0.25 \mathrm{~g}$ of dried historical cartilage or tissue. Although only partial mitochondrial D-loop sequences were recovered, characterization of haplotypes is particularly informative in the white shark, as natal philopatry leads to certain haplotypes becoming characteristic of specific geographic areas (Pardini et al. 2001). Hence, 
the approach outlined here allows investigation of genetic changes between historical and contemporary local shark stocks and identification of the putative origin of individuals - aspects central to estimates of stock viability and assessment of anthropogenic impacts.

Ahonen \& Stow (2008) demonstrated successful DNA extraction and PCR amplification from only $44 \%$ of historical jaws or teeth collected 20 to $40 \mathrm{yr}$ earlier from whaler sharks (family Carcharhinidae), grey nurse sharks Carcharias taurus, tiger shark Galeocerdo cuvier, and school sharks Galeorhinus galeus; teeth of all these species, except the nurse shark, possess a pulp cavity, which generally yields better quality DNA than that recovered from osteodentine. From these species they reported a $608 \mathrm{bp}$ mtDNA D-loop sequence derived from amplicons of ca. $700 \mathrm{bp}$ obtained using generic primers designed from a contemporary grey nurse shark. In contrast, our approach uses species-specific primers to target smaller overlapping amplicons, ensuring product fidelity in most historical, badly adulterated, and degraded material from teeth/jaws and tissue. This strategy reliably produced 6 amplicons of between 135 and $286 \mathrm{bp}$ for reconstituting a mtDNA D-loop sequence of up to $874 \mathrm{bp}$ from contemporary South African shark teeth and $749 \mathrm{bp}$ from historical material. Yet the poorer quality and low yield of DNA from the osteodentine of contemporary white shark teeth suggest use of historical teeth may be possible but challenging.

In contrast to poor yields from teeth, rehydration of historical dried tissue and brittle cartilage gave good yields of genomic DNA. Additionally, variable success using primers producing larger products was greatly improved by implementation of a semi-nested PCR approach, often advantageous when working with degraded historical samples. To recover the full spectrum of haplotypes from historical material for comparison with contemporary samples, it was important to use additional primers (such as those for D-loop7F), to span areas of the sequence which were inaccessible due to the strategy of using a series of small overlapping amplicons, where informative polymorphic sites differentiating haplotypes were concealed within primer sites (e.g. Positions 386 and 451 within Dloop1R and D-loop3F primers, respectively) (Fig. 1). This highlights the importance of designing many overlapping primer sets to resolve false positives, polymorphisms within the primer sequence, and PCR artefacts, thereby providing sufficient fidelity to legitimately compare haplotype diversity between historical and contemporary materials.
Consistent, reproducible amplifications were obtained using DNA extracted from dried finclips (GWMD20 and 21), jaw cartilage preserved with lacquer (GWMD15), and from dried condocranium tissue, the oldest sample used in this study (GWMD10, collected in 1885), suggesting that tissue type and mode of preservation impact amplification success. Amplification of larger products may be possible with better sample preservation and from species with teeth containing a pulp cavity (Ahonen \& Stow 2008). Whilst recovery of ancient/historical DNA is technically difficult, it promises novel and potentially important data of conservation significance for rare and endangered species (Alter et al. 2012).

The origins, population connectivity, and genetic diversity of white sharks in the Mediterranean are poorly known. All satellite tagging expeditions to date have been unsuccessful, and current hypotheses rely on historical capture and sighting data (Fergusson 2002). The first genetic study of contemporary Mediterranean material indicated this population exhibited little genetic diversity and suggested the ancestors of these sharks came not, as might be expected, from the adjacent Atlantic, but from distant Pacific stocks - perhaps a consequence of an anomalous migratory event (Gubili et al. 2011). Our recent results do not counter this view, with 3 haplotypes apparent in the 5 historical Mediterranean samples, 3 individuals sharing the contemporary Mediterranean haplotype (H2), and 2 new haplotypes (H1 \& H24) clustering with contemporary Pacific sequences. This placement of haplotypes obtained from historical material with an accepted phylogeny derived from contemporary Mediterranean and Pacific samples supports the validity of our current methodological approach. Notably, 1 historic haplotype (H1) clusters with an Australia/New Zealand haplotype (H9), differing by only 2 mutational steps. This is no more distant than other contemporary Australian haplotypes, which raises the intriguing possibility that Mediterranean white sharks have multiple, and possibly more recent, Pacific founders. However, because this analysis is based on less mtDNA D-loop sequence than reported in Gubili et al. (2011), it is impossible to differentiate between the null hypothesis of $\mathrm{H} 1$ evolving in situ in the Mediterranean from founding stock, the most likely explanation for H24, or the alternative hypothesis that it indicates multiple, and perhaps more recent, migrations from the Pacific. It is notable that these additional haplotypes are present in the oldest (19th century) samples. 
If further analysis of historical Mediterranean white shark material, for both mtDNA and nuclear markers, does not refute the conjecture of a potentially small, genetically isolated, and highly inbred population, then concerns should be raised about its ability to cope with rapid environmental and ecological change (Cheptou \& Donohue 2011). As a result of current declines (Cavanagh \& Gibson 2007, Storai et al. 2011) and the rarity of contemporary material, it is imperative that museum and trophy specimens found throughout the Mediterranean region and Europe are utilized to refine estimates of connectivity, decline of genetic diversity, and contemporary gene flow to assess the viability of Mediterranean white shark stocks.

Recourse to historical Mediterranean material may be the only way to study the genetic diversity of this threatened population, as artisanal fisheries throughout the region complicate management strategies, and contemporary captures are probably sold at market before they can be sampled (S. Canese pers. obs.). Yet reports of pregnant females off Tunisia and of neonates in the Aegean Sea suggest key nursery sites for this species are located within highly overexploited and data-deficient regions (Saïdi et al. 2005, Kabasakal 2008). In support, as a response to large declines in predatory sharks (Ferretti et al. 2008) and rapidly shifting trophic systems, increased pressure has been placed on regional fisheries management organizations throughout the Mediterranean to improve species-specific catch and landings data, prohibit finning and encourage full utilization, and assess management needs for elasmobranch conservation (Camhi et al. 2009).

Three out of 5 Mediterranean historical samples were of the contemporary haplotype, suggesting haplotypes of the 2 oldest samples have not been seen in the contemporary population sampled to date. Hence, this retrospective analysis of tissue archives, with the caveat of very small sample sizes and partial sequences, confirms the lack of haplotype diversity in contemporary sharks and tentatively suggests a loss of genetic diversity (Table 3) in the last $100 \mathrm{yr}$ - a period during which white shark stocks and habitats have suffered degradation. Necessarily, the ecological implications of a lack, possibly as a result of recent loss, of genetic diversity in an apex predator extend beyond the demise of a single species.

\section{CONCLUSIONS}

This study demonstrates the validity of our approach for extraction, amplification, and sequencing of genomic DNA from white shark teeth and historical material. Historical DNA sequences can be combined with contemporary samples to increase sample size for rare species, affording estimates of changes in population and demographic parameters across centuries. Data from this approach are particularly relevant to conservation management of an endangered K-selected species exhibiting philopatric behaviour. Our findings give no cause for complacency, suggesting haplotype diversity of contemporary Mediterranean individuals is depauperate compared with that of other populations.

Acknowledgements. This work was supported by Aberdeen University, the Marine Biological Association and Save Our Seas Foundation (SOSF). We thank Mr Oliver Crimmen, Dr Colin MacLeod, Dr Sharon Mitchell, and Patricia Crombie for their support, Dr Takashi Sawada for valuable comments on elasmobranch tooth formation, and Professor Richard Aspden for use of the freezer mill for grinding osteodentine. Thanks to Steffano Vanni, Giuseppe Guarrasi, Enrico Bellia, Helmut Wellendorf, Radek Šanda, Peter Adamik, and Georges Lenglet for allowing access to material from museum and private collections.

\section{LITERATURE CITED}

Ahonen H, Stow AJ (2008) Shark jaws and teeth: an unexploited resource for population genetic studies. J Fish Biol 73:450-455

Alter SE, Newsome SD, Palumbi SR (2012) Pre-whaling genetic diversity and population ecology in eastern Pacific gray whales: insights from ancient DNA and stable isotopes. PLoS ONE 7:e35039

Avise JC (1995) Mitochondrial DNA polymorphism and the connection between genetics and demography of relevance to conservation. Conserv Biol 9:686-690

> Baum JK, Myers RA, Kehler DG, Worm B, Harley SJ, Doherty PA (2003) Collapse and conservation of shark populations in the Northwest Atlantic. Science 299:389-392

Bonfil R, Meÿer M, Scholl MC, Johnson R and others (2005) Transoceanic migration, spatial dynamics, and population linkages of white sharks. Science 310:100-103

Blower DC, Pandolfi JM, Bruce BD, Gomez-Cabrera MDC, Ovenden JR (2012) Population genetics of Australian white sharks reveals fine-scale spatial structure, transoceanic dispersal events and low effective population sizes. Mar Ecol Prog Ser 455:229-244

Burgess GH, Bruce BD, Cailliet GM, Goldman KJ and others (2014) A re-evaluation of the size of the white shark (Carcharodon carcharias) population off California, USA. PLoS ONE 9:e98078

Camhi MD, Valenti SV, Fordham SV, Fowler SL, Gibson C (2009) The conservation status of pelagic sharks and rays: report of the IUCN shark specialist group pelagic shark Red List workshop. IUCN Species Survival Commission Shark Specialist Group, Newbury

Cavanagh RD, Gibson C (2007) Overview of the conservation status of cartilaginous fishes (chrondrichthyans) in the Mediterranean Sea (No. 3). IUCN, Gland

Chang CH, Shao KT, Lin YS, Fang YC, Ho HC (2014) The complete mitochondrial genome of the great white shark, Carcharodon carcharias (Chondrichthyes, Lamnidae). Mitochondrial DNA 25:357-358 
Chapple TK, Jorgensen SJ, Anderson SD, Kanive PE, Klimley AP, Botsford LW, Block BA (2011) A first estimate of white shark Carcharodon carcharias, abundance off Central California. Biol Lett 7:581-583

Cheptou PO, Donohue K (2011) Environment-dependent inbreeding depression: its ecological and evolutionary significance. New Phytol 189:395-407

Cliff G, Dudley SFJ, Davis B (1989) Sharks caught in the protective gill nets off Natal, South Africa. 2. The great white shark Carcharodon carcharias (Linnaeus). S Afr J Mar Sci 8:131-144

> Curtis TH, McCandless CT, Carlson JK, Skomal GB and others (2014) Seasonal distribution and historic trends in abundance of white sharks, Carcharodon carcharias, in the western North Atlantic Ocean. PLoS ONE 9:e99240

> Domier ML, Nasby-Lucas N (2013) Two-year migration of adult female white sharks (Carcharodon carcharias) reveals widely separated nursery areas and conservation concerns. Anim Biotelem 1:2

> Dudgeon CL, Blower DC, Broderick D, Giles JL and others (2012) A review of the application of molecular genetics for fisheries management and conservation of sharks and rays. J Fish Biol 80:1789-1843

Dulvy NK, Forrest RE (2009) Life histories, population dynamics, and extinction risks in chondrichthyans. In: Carrier JC, Musick JA, Heithaus MR (eds) Sharks and their relatives. II. Biodiversity, adaptive physiology, and conservation. CRC Press, Boca Raton, FL, p 635-676

> Dulvy NK, Fowler SL, Musick JA, Cavanagh RD and others (2014) Extinction risk and conservation of the world's sharks and rays. eLife 3:e00590

Fergusson IK (2002) Occurrence and biology of the great white shark, Carcharodon carcharias in the central Mediterranean Sea: a review. In: Vacchi M, La Mesa G, Serena F, Sèret B (eds) Proc $4^{\text {th }}$ EEA Meeting. ICRAM, APRAT \& SFI, Palermo, p 7-10

Ferretti F, Myers RA, Serena F, Lotze HK (2008) Loss of large predatory sharks from the Mediterranean Sea. Conserv Biol 22:952-964

Filatov DA (2002) A software for preparation and evolutionary analysis of DNA sequence data sets. Mol Ecol Notes 2:621-624

Fulton TL, Stiller M (2012) PCR amplification, cloning, and sequencing of ancient DNA. In: Shapiro B, Hofreiter M (eds) Ancient DNA: methods and protocols. Methods Mol Biol 840:111-119

Gubili C (2009) Application of molecular genetics for conservation of the great white shark, Carcharodon carcharias, L. 1758. PhD thesis, University of Aberdeen

> Gubili C, Bilgin R, Kalkan E, Karhan SU and others (2011) Antipodean white sharks on a Mediterranean walkabout? Historical dispersal leads to genetic discontinuity and an endangered anomalous population. Proc R Soc Lond B Biol Sci 278:1679-1686

> Guindon S, Gascuel O (2003) A simple, fast and accurate algorithm to estimate large phylogenies by maximum likelihood. Syst Biol 52:696-704

> Guindon S, Dufayard JF, Lefort V, Anisimova M, Hordijk W, Gascuel O (2010) New algorithms and methods to estimate maximum-likelihood phylogenies: assessing the performance of PhyML 3.0. Syst Biol 59:307-321

> Höss M, Pääbo S (1993) DNA extraction from Pleistocene bones by a silica-based purification method. Nucleic Acids Res 21:3913-3914

Jewell OJD, Johnson RL, Gennari E, Bester MN (2013) Fine scale movements and activity areas of white sharks (Carcharodon carcharias) in Mossel Bay, South Africa. Environ Biol Fishes 96:881-894
Jorgensen SJ, Reeb CA, Chapple TK, Anderson S and others (2010) Philopatry and migration of Pacific white sharks. Proc R Soc Lond B Biol Sci 277:679-688

Kabasakal H (2008) Two recent records of the great white sharks, Carcharodon carcharias (Linnaeus, 1758) (Chondrichthyes: Lamnidae), caught in Turkish waters. Acta Adriatica 49(2):125-135

Kabasakal H (2014) The status of the great white shark (Carcharodon carcharias) in Turkey's waters. Mar Biodivers Rec 7:e109

Kock A, O'Riain JM, Mauff K, Meÿer M, Kotze D, Griffiths C (2013) Residency, habitat use and sexual segregation of white shark, Carcharodon carcharias in False Bay, South Africa. PLoS ONE 8:e55048

Librado P, Rozas J (2009) DnaSP v5: a software for comprehensive analysis of DNA polymorphism data. Bioinformatics 25:1451-1452

McClenachan L, Cooper AB, Carpenter KE, Dulvy NK (2012) Extinction risk and bottlenecks in the conservation of charismatic marine species. Conserv Lett 5:73-80

McMenamin SK, Hadly EA (2012) Ancient DNA assessment of tiger salamander population in Yellowstone National Park. PLoS ONE 7:e32763

Pääbo S (1989) Ancient DNA: extraction, characterization, molecular cloning, and enzymatic amplification. Proc Natl Acad Sci USA 86:1939-1943

> Paetkau D, Slade R, Burden M, Estoup A (2004) Genetic assignment methods for the direct, real-time estimation of migration rate: a simulation-based exploration of accuracy and power. Mol Ecol 13:55-65

> Pardini AT, Jones CS, Noble LR (2001) Sex-biased dispersal of great white sharks. Nature 412:139-140

> Pfeiffer H, Steighner R, Fisher R, Mörnstad H, Yoon CL, Holland MM (1998) Mitochondrial DNA extraction and typing from isolated dentin-experimental evaluation in a Korean population. Int J Legal Med 111:309-313

Pinsky ML, Palumbi SR (2014) Meta-analysis reveals lower genetic diversity in overfished populations. Mol Ecol 23: 29-39

Posada D (2008) jModelTest: phylogenetic model averaging. Mol Biol Evol 25:1253-1256

Saïdi B, Bradai MN, Bouain A, Guelorget O, Capape C (2005) Capture of a pregnant female white shark, Carcharodon carcharias (Lamnidae) in the Gulf of Gabes (southern Tunisia, Central Mediterranean) with comments on oophagy in sharks. Cybium 29:303-307

Salzburger W, Ewing GB, Von Haeseler A (2011) The performance of phylogenetic algorithms in estimating haplotype genealogies with migration. Mol Ecol 20: 1952-1963

Sambrook J, Fritsch EF, Maniatis T (1989) Molecular cloning: a laboratory manual, $2^{\text {nd }}$ edn. Cold Spring Harbor Press, Cold Spring Harbor, NY

> Spielman D, Brook BW, Frankham R (2004) Most species are not driven to extinction before genetic factors impact them. Proc Natl Acad Sci USA 101:15261-15264

Storai T, Zinzula L, Repetto S, Zuffa M, Morgan A, Mandelman J (2011) Bycatch of large elasmobranchs in the traditional tuna traps (tonnare) of Sardinia from 1990 to 2009. Fish Res 109:74-79

Valentine K, Duffield DA, Patrick LE, Hatch DR, Butler VL, Hall RL, Lehman N (2008) Ancient DNA reveals genotype relationships among Oregon populations of the sea otter (Enhydra lutris). Conserv Genet 9:933-938

Vennemann TW, Hegner E, Cliff G, Benz GW (2001) Isotopic composition of recent shark teeth as a proxy for environmental conditions. Geochim Cosmochim Acta 65: 1583-1599

Submitted: August 5, 2014; Accepted: December 22, 2014

Proofs received from author(s): April 3, 2015 